\title{
A year in diabetic nephropathy
}

\author{
JOVANNA TSOUTSOUKI, ${ }^{1}$ TAHSEEN AHMAD CHOWDHURY²
}

\begin{abstract}
Whilst 2020 was a year of unique healthcare challenges, in people with type 2 diabetes and diabetic kidney disease (DKD), it was a year of seminal progress. Randomised clinical trials have shown a significant benefit of sodium-glucose transporter- 2 inhibitors in patients with DKD, and guidelines now suggest these drugs should be considered in all patients with type 2 diabetes and DKD irrespective of glucose control. Glucagon-like peptide-1 receptor agonists have shown some benefit in reducing progression of albuminuria in DKD, and should also be considered early in the therapeutic pathway. There are new guidelines on the management of post-transplant diabetes, and some new ideas in the management of diabetes in patients on haemodialysis. This article aims to review the year in diabetic nephropathy.

Br J Diabetes 2021;21:100-109
\end{abstract}

Key words: diabetes mellitus, type 2, nephropathy, post-transplant diabetes

\section{Introduction}

It is estimated that $40 \%$ of people living with type 2 diabetes (T2D) have diabetic kidney disease (DKD). ${ }^{1}$ DKD is defined as persistently reduced estimated glomerular filtration rate (eGFR) $<60 \mathrm{~mL} / \mathrm{min} /$ $1.73 \mathrm{~m}^{2}$ with micro- or macro-albuminuria. ${ }^{2} \mathrm{~T} 2 \mathrm{D}$ is the commonest cause of chronic kidney disease (CKD) worldwide requiring renal replacement therapy (RRT). ${ }^{3} \mathrm{CKD}$ and albuminuria are independent predictors of cardiovascular morbidity and mortality. ${ }^{4}$

In this article we review developments in the last year in patients with T2D and DKD, with a focus on new agents, new guidance on management of post-transplant diabetes mellitus (PTDM), and possible interventions in people with T2D on haemodialysis (HD).

\section{New agents in diabetic kidney disease (DKD)}

Patients with DKD are exemplars of multi-morbidity, often living with a number of long-term conditions and frailty. Treatment of

Specialist Registrar in Endocrinology and Diabetes, Department of Diabetes, The Royal London Hospital, London, UK

2 Consultant in Diabetes, Department of Diabetes, The Royal London Hospital, London, UK

Address for correspondence: Dr Tahseen Ahmad Chowdhury Consultant in Diabetes, Department of Diabetes, The Royal London Hospital, Whitechapel, London E1 1BB, UK

E-mail: Tahseen.chowdhury@nhs.net

https://doi.org/10.15277/bjd.2021.293
DKD involves management of hypertension with angiotensin converting enzyme inhibitors (ACEI) or angiotensin receptor blockers (ARB), improvement in glucose control individualised to the patient, management of cardiovascular risk factors, regular monitoring of renal function and screening for other complications. ${ }^{5}$ Multidisciplinary management with nephrologists is desirable when CKD is progressive. A number of interventions, such as combined ACEI/ARB, ${ }^{6}$ direct renin inhibitors, ${ }^{7}$ bardoxolone $^{8}$ and endothelin-A receptor antagonists ${ }^{9}$ have been tested in $D K D$, with no evidence of benefit.

Cardiovascular outcomes trials (CVOTs) of newer agents in T2D have led to a wealth of cardiovascular and renal outcome data which have informed clinical practice.

\section{Sodium-glucose transporter-2 inhibitors (SGLT2i)}

Sodium-glucose transporter-2 inhibitors (SGLT2i) act on the proximal tubule to inhibit glucose reabsorption, promote glycosuria and result in improvements in glucose and body weight. As renal function declines, less glucose is filtered hence attenuating the anti-hyperglycaemic efficacy of these agents in CKD. ${ }^{10}$ Several studies, however, suggest significant benefit in DKD independent of glucose control. Table 1 outlines the studies of SGLT2i in DKD.

In contrast to ACEI/ARBs, renoprotective effects of SGLT2i are thought to be mediated by tubuloglomerular feedback, natriuresis and glucose-induced osmotic diuresis which reduce intraglomerular pressure. ${ }^{11}$

\section{Empagliflozin}

In the EMPA-REG OUTCOME study, empagliflozin was shown to be effective and safe in patients with mild renal impairment (mean eGFR $74.1 \mathrm{~mL} / \mathrm{min} / 1.73 \mathrm{~m}^{2}$ ) and established cardiovascular disease (CVD). ${ }^{12}$ Empagliflozin reduced all-cause mortality by $32 \%$ (hazard ratio (HR) 0.68 [95\% confidence interval (CI) 0.57 to 0.82 ]; $p<0.001$ ), hospitalisation for heart failure (hHF) by $35 \%$ (HR 0.65 [0.50 to 0.85$] ; p=0.002$ ) and cardiovascular-related death by $38 \%$ (HR 0.62 [0.49 to 0.77 ]; $p<0.001$ ). In a subgroup analysis, the EMPA-REG RENAL study, a $38 \%$ reduction in macroalbuminuria onset, $44 \%$ reduction in doubling serum creatinine and $55 \%$ reduction in patients requiring RRT was seen across all CKD stages. ${ }^{13}$

The EMPEROR-Reduced trial examined participants with heart failure and mean eGFR $62 \mathrm{~mL} / \mathrm{min} / 1.73 \mathrm{~m}^{2}, 50 \%$ of whom had T2D. ${ }^{14}$ Empagliflozin led to a significantly lower rate of eGFR decline compared with placebo $\left(-0.55\right.$ vs $-2.28 \mathrm{~mL} / \mathrm{min} / 1.73 \mathrm{~m}^{2}$; $\mathrm{p}<0.001$ ). The risk of dialysis/transplantation or sustained reduction 
Table 1 Cardiovascular and renal outcome studies using sodium-glucose transporter-2 inhibitors (SGLT-2i)

\begin{tabular}{|c|c|c|c|c|}
\hline \multirow{2}{*}{$\begin{array}{l}\text { Trial } \\
\text { Intervention } \\
\text { (N) } \\
\text { Median follow-up }\end{array}$} & \multicolumn{2}{|c|}{ Study population characteristics } & \multirow{2}{*}{$\begin{array}{l}\text { Cardiovascular } \\
\text { outcomes }\end{array}$} & \multirow{2}{*}{$\begin{array}{l}\text { Renal } \\
\text { outcomes }\end{array}$} \\
\hline & General & Renal & & \\
\hline \multicolumn{5}{|l|}{ Dapagliflozin } \\
\hline 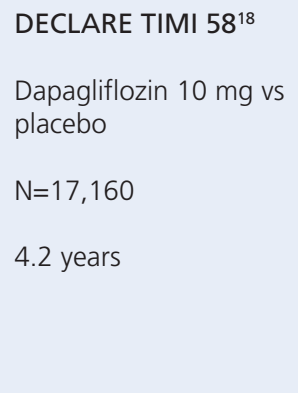 & $\begin{array}{l}\text { T2D }(100 \%) \\
\text { Established CVD } \\
(40.6 \%) \\
\text { CV risk factors }(59.4 \%) \\
\text { ACE-I/ARB }(86.7 \%)\end{array}$ & $\begin{array}{l}\text { eGFR }\left(\mathrm{mL} / \mathrm{min} / 1.73 \mathrm{~m}^{2}\right) \\
\text { Mean } 85 \\
\geq 90(47.6 \%) \\
60-90(45.1 \%) \\
<60(7.4 \%) \\
\text { Albuminuria }(\mathrm{mg} / \mathrm{g}) \\
<30(69.1 \%) \\
\geq 30-\leq 30(23.9 \%) \\
>300(6.9 \%)\end{array}$ & $\begin{array}{l}17 \% \text { reduction } \mathrm{CV} \text { death or } \mathrm{hHF} \\
\text { (HR } 0.83[0.73 \text { to } 0.95] ; p=0.005 \text { ) } \\
\text { No effect on MACE } \\
\text { (HR } 0.93 \text { [0.84 to } 1.03] ; p=0.17 \text { ) } \\
\text { No significant difference in CV } \\
\text { death, death from any cause }\end{array}$ & $\begin{array}{l}47 \% \text { RRR i } \\
\text { composite } \\
\text { (HR } 0.53[0 \\
p<0.0001 \text { ) } \\
59 \% \text { RRR i } \\
\text { or renal de } \\
\text { (HR } 0.41 \text { [0 } \\
p=0.012 \text { ) } \\
\text { Reduced e } \\
3.4 \text { years }\end{array}$ \\
\hline DAPA-CKD ${ }^{17}$ & T2D (67.5\%) & eGFR $\left(\mathrm{mL} / \min / 1.73 \mathrm{~m}^{2}\right)$ & $29 \%$ reduction in the composite & $44 \%$ red \\
\hline $\begin{array}{l}\text { Dapagliflozin } 10 \mathrm{mg} \text { vs } \\
\text { placebo }\end{array}$ & Established CVD (37\%) & $\begin{array}{l}\geq 60(10 \%) \\
45-<60(31 \%)\end{array}$ & (HR 0.71 [0.55 to 0.92$] ; p=0.009)$ & $\begin{array}{l}(H R 0.56[0 \\
p<0.001)\end{array}$ \\
\hline $\mathrm{N}=4,304$ & $\begin{array}{l}\text { Nearly all patients on } \\
\text { an ACE-I/ARB }\end{array}$ & $\begin{array}{l}30-<45(44.1 \%) \\
<30(14.5 \%)\end{array}$ & $\begin{array}{l}31 \% \text { reduction in death from } \\
\text { any cause }\end{array}$ & \\
\hline 2.4 years & & $\begin{array}{l}\text { Albuminuria }(\mathrm{mg} / \mathrm{g}) \\
\text { Range } 200-5000 \\
>1000(48.3 \%) \\
\text { Mean/median } 949\end{array}$ & (1) & \\
\hline DAPA-HF ${ }^{16}$ & $\mathrm{~T} 2 \mathrm{D}(45 \%)$ & $\begin{array}{l}\text { eGFR }\left(\mathrm{mL} / \mathrm{min} / 1.73 \mathrm{~m}^{2}\right) \\
\text { eGFR }>30\end{array}$ & $\begin{array}{l}25 \% \text { reduction in CV death or } \\
\mathrm{hHF}\end{array}$ & $\begin{array}{l}39 \% \text { non-s } \\
\text { reduction }\end{array}$ \\
\hline$N=4644$ & NYHA $2,3,4, E F \leq 40 \%$ & $\begin{array}{l}\text { Mean } 66 \\
<60(40.6 \%)\end{array}$ & (HR 0.75 [0.65 to 0.85$] ; p<0.001)$ & $\begin{array}{l}\text { renal funct } \\
\text { (HR } 0.71[0 .\end{array}$ \\
\hline 18.2 months & $\begin{array}{l}\text { Majority of patients on } \\
\text { ACE-I/ARB }\end{array}$ & & $\begin{array}{l}17 \% \text { reduction in all-cause } \\
\text { mortality } \\
\text { (HR } 0.83[0.71 \text { to } 0.97])\end{array}$ & $\begin{array}{l}\text { Smaller eG } \\
\text { year (dapas } \\
(-1.41-0 .\end{array}$ \\
\hline
\end{tabular}

Renal

outcomes

Dapagliflozin

(HR 0.83 [0.71 to 0.97])

$47 \%$ RRR in the renal composite*

(HR 0.53 [0.43 to 0.66]; $\mathrm{p}<0.0001)$

$59 \%$ RRR in risk of ESKD or renal death (HR 0.41 [0.20 to 0.82]; $\mathrm{p}=0.012$ )

Reduced eGFR decline at 3.4 years

$44 \%$ reduction in the renal composite $t$ (HR 0.56 [0.45 to 0.68]; $\mathrm{p}<0.001)$

$39 \%$ non-significant reduction in worsening renal functiont (HR 0.71 [0.44 to 16]; $p=0.17$ )

Smaller eGFR decline per year (dapagliflozin -1.09 $(-1.41,-0.78)$ vs placebo $-2.87(-3.19,-2.55)(p<0.001)$

\section{Empagliflozin}

\section{EMPA-REG OUTCOME ${ }^{11}$}

Empagliflozin 10 mg/

$15 \mathrm{mg}$ vs placebo

3.1 years

$\mathrm{N}=7,020$

\section{EMPEROR REDUCED 13}

Empagliflozin $10 \mathrm{mg}$ vs placebo

$N=3,730$

16 months
T2D (100\%)

Established CVD (99\%)

ACE-I/ARB (80.7\%)
eGFR $\left(\mathrm{mL} / \mathrm{min} / 1.73 \mathrm{~m}^{2}\right)$ eGFR $>30$

Mean $74 \cdot 1$

45-59 (17.8\%)

30-44 (7.7\%)

Albuminuria $(\mathrm{mg} / \mathrm{g})$ 30-300 (28.7\%) $>300(11 \%)$

eGFR $\left(\mathrm{mL} / \mathrm{min} / 1.73 \mathrm{~m}^{2}\right)$

Mean 62

eGFR $<60(48 \%)$
$14 \%$ reduction in 3p-MACE§ (HR 0.86 [0.74 to 0.99])

$38 \%$ RRR in CV death (HR 0.62 [0.49 to 0.77]; $p<0.001$ )

$35 \%$ reduction in $\mathrm{hHF}$ (HR 0.65 [0.50 to 85]; $p=0.002$ )

$32 \%$ reduction in death from any cause

(HR 0.68 [0.57 to 0.82]; $p<0.001$ )

No effect on Ml/stroke

$25 \%$ reduction in $\mathrm{hHf}$ or $\mathrm{CV}$ death (HR 0.75 [0.65 to 0.86]; $p<0.001$ )

$\mathrm{EF} \leq 40 \%$

$\mathrm{EF}<30 \%(73 \%)$

$>30 \%(27 \%)$

hHF in last 12 months or NT-proBNP of at least $1000 \mathrm{pg} / \mathrm{mL}$ (79\%)

Majority on ACEi/ARB
$46 \%$ reduction in composite renal outcomet†

(HR 0.54 [0.40 to 0.75]; $\mathrm{p}<0.001$ )

$39 \%$ reduction in incident or worsening of nephropathy (HR 0.61 [0.53 to 0.70]; $\mathrm{p}<0.001$ )

$50 \%$ reduction in renal composite renal $\S \S$ (HR 0.50 [0.32 to 0.77]; significance level not specified) 
Table 1 Cardiovascular and renal outcome studies using sodium-glucose transporter-2 inhibitors (SGLT-2i) continued

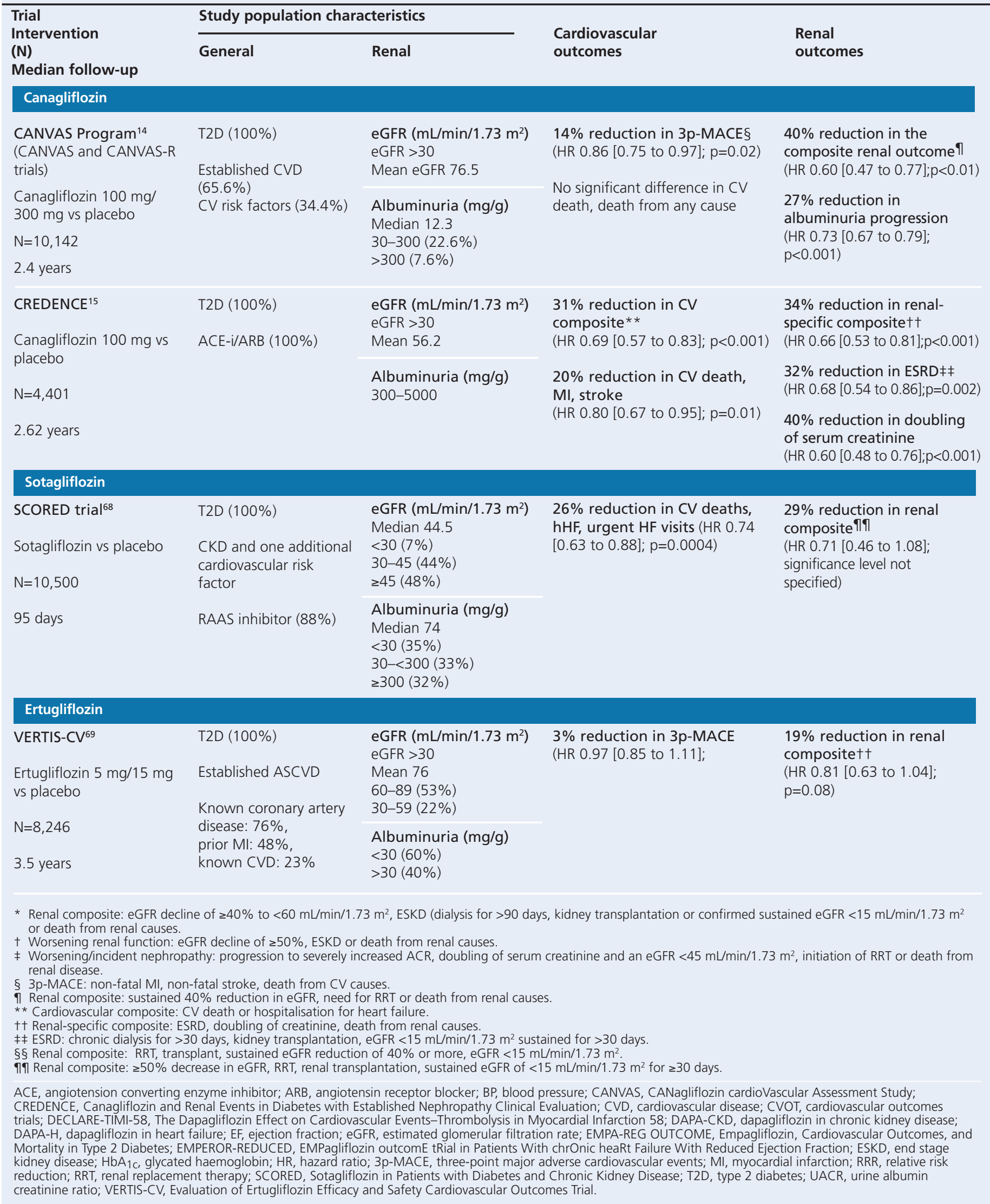


in eGFR was halved in the empagliflozin group (HR 0.50 [0.32 to 0.77]; $p<0.001)$.

A specific study of empagliflozin in patients with CKD, many of whom will have T2D, (EMPA-KIDNEY) is due to report in 2022.

\section{Canagliflozin}

Cardiovascular outcomes of canagliflozin were studied in the CANVAS program, involving 10,142 participants with T2D receiving standard care with inadequate glycaemic control, established CVD or high cardiovascular risk. ${ }^{15}$ Mean eGFR was $76.5 \mathrm{~mL} / \mathrm{min} /$ $1.73 \mathrm{~m}^{2}$ and median albumin/creatinine ratio (ACR) was $12.3 \mathrm{mg} / \mathrm{g}$. Canagliflozin led to a lower three-point major adverse cardiovascular outcomes (3p-MACE) (HR 0.86 [0.75 to 0.97]; $p<0.001$ ), with the largest benefit seen in stroke reduction in subgroups with more advanced CKD (HR 0.56 for eGFR 45$60 \mathrm{~mL} / \mathrm{min} / 1.73 \mathrm{~m}^{2}$ and 0.32 for $30-45 \mathrm{~mL} / \mathrm{min} / 1.73 \mathrm{~m}^{2}$ group).

Specific renal outcomes with canagliflozin in people with T2D were examined in the CREDENCE study. ${ }^{16} \mathrm{~A}$ total of 4,401 patients had albuminuric CKD (mean eGFR $56.2 \mathrm{~mL} / \mathrm{min} / 1.73 \mathrm{~m}^{2}$ ) and included patients with eGFR $\geq 30 \mathrm{~mL} / \mathrm{min} / 1.73 \mathrm{~m}^{2}$. Median ACR was $927 \mathrm{mg} / \mathrm{g}$. Canagliflozin was associated with a 34\% reduction (HR 0.66 [0.53 to 0.81 ]; $p<0.001$ ) in the renal specific composite (doubling of baseline creatinine, end stage renal disease (ESRD) or death from renal causes). Canagliflozin reduced 3p-MACE by 20\% (HR 0.80 [0.67 to 0.95$] ; p<0.01$ ) and hHF by 39\% (HR 0.61 [0.47 to 90.8]; $p<0.001$ ). The numbers needed to treat (NNT) to prevent one case of doubling of serum creatinine, ESRD or death from renal or cardiovascular cause was 21.

Efficacy was seen across all stages of CKD, with highest efficacy in eGFR $45-60 \mathrm{~mL} / \mathrm{min} / 1.73 \mathrm{~m}^{2}$ and urinary ACR $>1000 \mathrm{mg} / \mathrm{g}$. Based on this evidence, canagliflozin is now considered an effective option for renal and cardiovascular protection in DKD and can be initiated in people with T2D and macroalbuminuria and eGFR $>30 \mathrm{~mL} / \mathrm{min} /$ $1.73 \mathrm{~m}^{2}$, as an add-on to ACEI, irrespective of glucose control.

\section{Dapagliflozin}

Three large trials have studied the effects of dapagliflozin, two of which (DAPA-HF ${ }^{17}$ and DAPA-CKD ${ }^{18}$ ) included people with and without diabetes. ${ }^{17-19}$ Overall, dapagliflozin demonstrated a benefit in reducing cardiovascular death and hHF, irrespective of the baseline cardiovascular risk or renal function, but did not reduce 3p-MACE. Dapagliflozin reduced the number of deaths from any cause in people with impaired renal function (DAPACKD) (HR 0.69 [0.53 to 0.88]; $\mathrm{p}=0.004$ ), irrespective of the baseline eGFR. In patients with eGFR 25-75 mL/min/1.73 $\mathrm{m}^{2}$ and albuminuria, dapagliflozin demonstrated a $44 \%$ reduction in the composite renal outcome (HR 0.56 [0.45 to 0.68]; $p<0.001$ ). ${ }^{18}$ The NNT to prevent doubling of serum creatinine, ESRD or death from cardiovascular or renal causes was 19.

In DECLARE TIMI 58, ${ }^{19}$ in people with T2D with either established CVD or multiple risk factors and relatively normal renal function (mean eGFR $85.2 \mathrm{~mL} / \mathrm{min}$ per $1.73 \mathrm{~m}^{2}$ ), dapagliflozin reduced eGFR decline $>40 \%$ by $46 \%$ (HR 0.54 [0.43 to 0.67]; $p<0.0001$ ) and $59 \%$ reduced incidence of ESRD or renal death (HR $0.41[0.20$ to 0.82 ]; $p=0.012$ ).

\section{Meta-analysis}

Meta-analysis confirms favourable effects of SGLT2i on the renal composite of doubling of serum creatinine (eGFR $40 \%$ decline), RRT initiation or renal-related death (RR 0.63 [0.56 to 0.71$]$ ), even in the presence of CVD or multiple risk factors (RR 0.67 [0.59 to 0.76]). ${ }^{20}$ The pooled NNT for renal outcomes was 67. SGLT2i also reduce albuminuria progression (RR 0.80 [0.76 to 0.84$]$ ). The renal and cardiovascular effects of SGLT2i are present across all stages of CKD, irrespective of baseline albuminuria. ${ }^{21,22}$ Importantly, however, the effects appear to be strongest amongst those patients with albuminuria, compared with those who are normoalbuminuric. The effect is additive to ACEl or ARB use.

These benefits have been confirmed also in an observational cohort study (CVD-REAL 3), ${ }^{23}$ examining 65,231 people with T2D over 14.9 months, 35,561 of whom were newly started on an SGLT2i. SGLT2i led to a reduced eGFR decline compared with other glucose-lowering drugs (between-group difference in rate of decline $1.53 \mathrm{~mL} / \mathrm{min} / 1.73 \mathrm{~m}^{2}$ per year [1.34 to 1.72 ]; $p<0.0001$ ). The composite end point of eGFR reduction by $50 \%$ or ESRD was also significantly lower with SGLT2i (HR 0.49 [0.35 to 0.67]; $p<0.0001$ ). Lower RRT incidence is also associated with use of SGLT2i compared with patients taking dipeptidylpeptidase-4 inhibitors (HR 0.32 [0.22 to 0.47 ]; $p<0.0001) .{ }^{24}$

Current UK licensing suggests that empagliflozin and dapagliflozin can be initiated at eGFR $\geq 60 \mathrm{~mL} / \mathrm{min} / 1.73 \mathrm{~m}^{2} .{ }^{25,26}$ Dapagliflozin should be discontinued at eGFR $<60 \mathrm{~mL} / \mathrm{min} / 1.73 \mathrm{~m}^{2}$, whilst empaglifozin should be stopped at eGFR $<45 \mathrm{~mL} / \mathrm{min} /$ $1.73 \mathrm{~m}^{2}$. It is likely, however, that on the basis of new evidence, dapagliflozin will gain a licence for use at eGFR $>30 \mathrm{~mL} / \mathrm{min} /$ $1.73 \mathrm{~m}^{2}$. Canagliflozin is approved for initiation in people with T2D with eGFR $\geq 30 \mathrm{~mL} / \mathrm{min} / 1.73 \mathrm{~m}^{2}$ and can be continued in eGFR $<30$ $\mathrm{mL} / \mathrm{min} / 1.73 \mathrm{~m}^{2}$ in the presence of albuminuria $\geq 300 \mathrm{mg} /$ day unless dialysis is initiated. ${ }^{27}$ ADA-EASD consensus guidelines recommend that SGLT2i can be used in any patient with T2D with HF or CKD. ${ }^{28}$

\section{Adverse effects}

The commonest adverse event is genital mycotic infections, which commonly occur early in treatment and responds well to over-thecounter medication. ${ }^{29}$ Urinary tract infections are less frequent.

SLGT2i may cause euglycaemic ketoacidosis, and careful patient education around sick day rules is needed, including avoidance prior to surgery and avoidance of ketogenic diets..$^{30} \mathrm{~A}$ reduction in bone mineral density and increased risk of fractures has been suggested, although meta-analysis has not confirmed this. ${ }^{31}$ CANVAS showed a slight increase in amputations associated with canagliflozin, which was not replicated in the CREDENCE study or with any other SGLT2i. Previous concerns regarding acute kidney injury (AKI) have been alleviated by more recent trials, and no increase in AKI has been seen in observational cohorts. ${ }^{32}$

\section{Glucagon-like peptide-1 receptor agonists (GLP-1RA)}

GLP-1RAs can be divided into incretin mimetics (exendin-4 analogues - exenatide/lixisenatide) or human GLP-1RA (albiglutide, liraglutide, dulaglutide, semaglutide). Elimination of exendin- 4 analogues relies on glomerular filtration, and hence they accumulate 
in renal insufficiency. They have not demonstrated improved outcomes in CVOTs. ${ }^{33,34}$ In contrast, human GLP-1RA are safe in CKD. ${ }^{35}$ Studies of GLP-1RAs in DKD are shown in Table 2.

Liraglutide, ${ }^{35,36}$ dulaglutide, ${ }^{37,38}$ and subcutaneous ${ }^{39}$ or oral ${ }^{40}$ semaglutide have demonstrated effective glycaemic control in T2D and CKD. Liraglutide has shown these effects in patients on dialysis, ${ }^{41}$ and was superior to placebo in people with T2D and moderate renal impairment..$^{35}$ In patients with moderate-severe $C K D$, weekly dulaglutide was non-inferior to insulin glargine. ${ }^{42}$ Oral semaglutide was superior to placebo both in weight and $\mathrm{HbA}_{1 \mathrm{c}}$ reduction in people with T2D and CKD, with no additional risk of adverse events. ${ }^{43}$

GLP-1RAs have shown promising results in CVOTs. Meta-analysis of the seven large GLP-1 trials of 56,004 patients showed a $12 \%$ reduction in 3p-MACE. ${ }^{44}$ Composite renal outcome was reduced by $17 \%$ for all GLP1-RAs, mainly due to a reduction in new macroalbuminuria.

These properties of GLP-1RAs have been linked to their direct actions on blood pressure, glucose and weight, but also to improving endothelial dysfunction and inflammation. ${ }^{45}$ They frequently cause an initial eGFR reduction upon administration, with subsequent plateauing. Human GLP-1RAs are approved for use at eGFR $\geq 15 \mathrm{~mL} / \mathrm{min} / 1.73 \mathrm{~m}^{2}$.

\section{Liraglutide}

Liraglutide has shown some renoprotective properties. ${ }^{36}$ People with T2D with established CVD or high CVD risk and mean eGFR $80 \mathrm{~mL} / \mathrm{min} / 1.73 \mathrm{~m}^{2}$ showed a $22 \%$ risk reduction (HR 0.78 [0.67 to 0.92 ]; $p=0.003$ ) in a pre-specified renal outcome (new onset macroalbuminuria, doubling serum creatinine, eGFR $<45 \mathrm{~mL} /$ $\mathrm{min} / 1.73 \mathrm{~m}^{2}$, need for RRT, death from renal disease), predominantly attributed to a $26 \%$ reduction in new onset persistent macroalbuminuria (HR 0.74 [0.60 to 0.91$] ; p=0.004$ ).

\section{Semaglutide}

SUSTAIN-6 involved 3,297 people with T2D and CVD, heart failure or CKD stage 3-5.39 Semaglutide decreased the incidence of non-fatal myocardial infarction by $26 \%$ and stroke by $39 \%$, but had no effect on hHF or cardiovascular death. Semaglutide led to a $36 \%$ reduction in the renal composite of new or worsening nephropathy (persistent macroalbuminuria, persistent doubling of serum creatinine or eGFR $<45 \mathrm{~mL} / \mathrm{min} / 1.73 \mathrm{~m}^{2}$ ) (HR 0.64 [0.46 to 0.88 ]; $p=0.005$ ), mainly due to reduction in new macroalbuminuria (HR 0.54 [0.34 to 0.77]; $p=0.001$ ). Post hoc analysis of SUSTAIN studies suggested favourable effects on decreasing onset of microalbuminuria. ${ }^{46}$

Renal effects of once-weekly subcutaneous semaglutide are being studied in the FLOW trial which includes people with T2D and CKD (eGFR 50-75 mL/min/1.73 $\mathrm{m}^{2}$ and ACR 300-5000 mg/g or eGFR $25-50 \mathrm{~mL} / \mathrm{min} / 1.73 \mathrm{~m}^{2}$ and ACR $100-5000 \mathrm{mg} / \mathrm{g}$ ). The primary end point is persistent eGFR decline ( $\geq 50 \%$ from baseline), ESRD, renal or cardiovascular death, and will report in 2024.47

\section{Dulaglutide}

In the REWIND study, dulaglutide was associated with a $15 \%$ re- duction in the composite renal outcome in patients with either established CVD or risk factors and a mean eGFR of $76.9 \mathrm{~mL}$ $\mathrm{min} / 1.73 \mathrm{~m}^{2}$, driven by a $23 \%$ reduction in macroalbuminuria onset (HR 0.77 [0.68 to 0.87]; $p=0.0001$ ). ${ }^{37}$

Dulaglutide has also shown superiority over insulin glargine on attenuating eGFR decline in T2D with moderate-severe CKD (eGFR reduction by $3.3 \mathrm{~mL} / \mathrm{min} / 1.73 \mathrm{~m}^{2} /$ year with glargine; eGFR reduction by $0.7 \mathrm{~mL} / \mathrm{min} / 1.73 \mathrm{~m}^{2} /$ year with dulaglutide). ${ }^{42}$ Risk of progression to ESRD or $>40 \%$ eGFR decline was also reduced with dulaglutide compared with glargine $(5.2 \%$ vs $10.8 \%$; $p=0.038)$.

Overall, the GLP-1RA data suggest a favourable effect in DKD, predominantly due to a reduction in the rate of appearance or progression of macroalbuminuria.

\section{Aldosterone receptor antagonist}

A recent study of the aldosterone receptor antagonist finerenone in 5,734 people with T2D and CKD showed some positive benefits. ${ }^{48}$ Patients included had eGFR $25-60 \mathrm{~mL} / \mathrm{min} / 1.73 \mathrm{~m}^{2}$ and urine ACR $30-300 \mathrm{mg} / \mathrm{g}$, and maximum tolerated ARB or ACEl therapy. The primary composite outcome of kidney failure, a sustained decrease of at least $40 \%$ in the eGFR from baseline or death from renal causes was reduced by $18 \%$ in the finerenone group (HR 0.82 [0.73 to 0.93$] ; p=0.001$ ). Hyperkalaemia necessitating cessation of finerenone occurred in $2.3 \%$ of patients treated.

\section{New guidance on post-transplant diabetes (PTDM)}

Solid organ transplantation (SOT) is a life changing therapy for hundreds of thousands of people worldwide. Advances in immunosuppression have led to dramatic improvements in graft and patient survival, but morbidity and mortality from CVD is high, with PTDM being an important contributor. PTDM is a distinct clinical entity that affects between $10 \%$ and $40 \%$ of SOT recipients, ${ }^{49}$ and confers a higher risk of graft failure and mortality. ${ }^{50}$ Recent guidance on the diagnosis, management and prevention of PTDM have been developed by the Association of British Clinical Diabetologists (ABCD) and Renal Association (RA) diabetic nephropathy clinical specialty group ${ }^{51}$ These guidelines do not include the management of patients undergoing pancreas transplantation.

\section{Pathogenesis}

Weight gain (due to glucocorticoids and fewer dietary restrictions) is common in patients post SOT. ${ }^{52}$ Risk factors for the development of PTDM are similar to T2D, but specific transplantrelated risks also contribute, including immunosuppression and infection (eg, hepatitis C).

Calcineurin is an important factor in $\beta$-cell function and growth, and calcineurin inhibitors have adverse effects on $\beta$-cell function leading to reduction in insulin secretion. ${ }^{53}$ Whilst tacrolimus is a highly effective immunosuppressant, it has a more potent adverse effect on $\beta$-cell function, leading more frequently to significant hyperglycaemia compared with ciclosporin. ${ }^{54}$

\section{Diagnosis}

Early hyperglycaemia is common in SOT recipients due to stress 
Table 2 Cardiovascular and renal outcome studies using glucagon-like peptide-1 receptor agonists (GLP-1RAs)

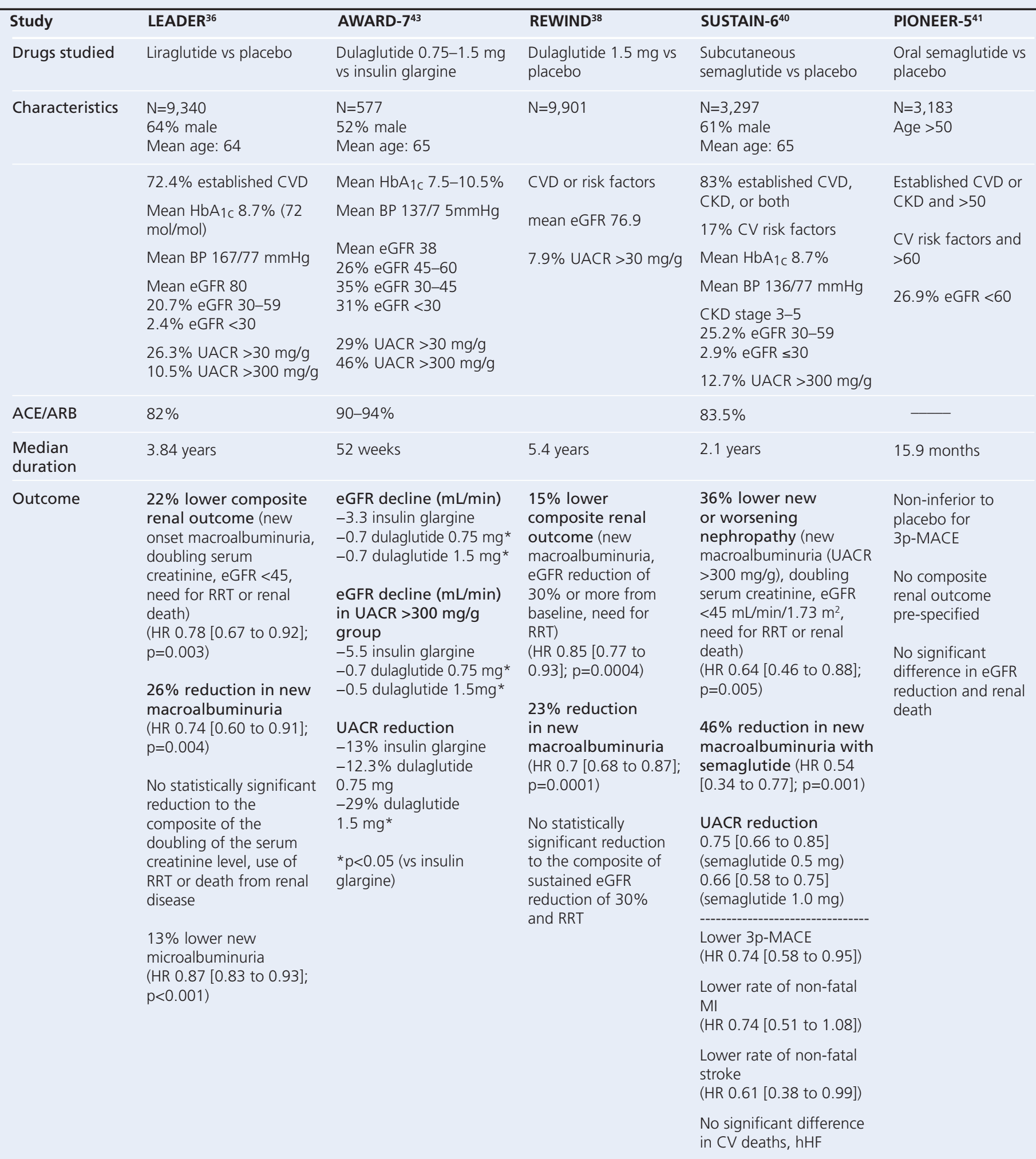

ACE, angiotension converting enzyme inhibitor; ARB, angiotensin receptor blocker; AWARD-7, dulaglutide versus insulin glargine in patients with type 2 diabetes and moderate to severe CKD; BP, blood pressure; CKD, chronic kidney disease; CVD, cardiovascular disease; CVOT, cardiovascular outcomes trials; eGFR, estimated glomerular filtration rate; $\mathrm{HbA}_{1}$, glycated haemoglobin; HR, hazard ratio; hHF, hospitalisation for heart failure; LEADER, Liraglutide Effect and Action in Diabetes: Evaluation of Cardiovascular Outcome Results; 3p-MACE, three point major adverse cardiovascular events; MI, myocardial infarction; PIONEER-6, Peptide Innovation for Early Diabetes Treatment; REWIND, dulaglutide and cardiovascular outcomes in type 2 diabetes; RRT, renal replacement therapy; SUSTAIN-6, Trial to Evaluate Cardiovascular and Other Long-term Outcomes with Semaglutide in Subjects with Type 2 Diabetes; UACR, urine albumin creatinine ratio. 
hyperglycaemia, infection, pain, immunosuppression and parenteral/enteral feeding. ${ }^{55} \mathrm{In}$ the immediate post-transplant period where doses of immunosuppression are high, screening for post-transplant hyperglycaemia should involve frequent capillary blood glucose (CBG) testing, predominantly later in the day (post lunch or evening meal). International consensus suggests a clear method of diagnosis of PTDM based on the oral glucose tolerance test or glycated haemoglobin $\left(\mathrm{HbA}_{1 \mathrm{c}}\right) \cdot{ }^{56}$ Interpretation of $\mathrm{HbA}_{1 \mathrm{c}}$ can, however, be problematic postoperatively and in patients with renal disease. It is therefore recommended that $\mathrm{HbA}_{1 c}$ only be used at least three months post-transplant, and prior to this, glucose tests should be undertaken.

\section{Management}

Early post-transplant hyperglycaemia requires active monitoring and management (Figure 1). Persistent hyperglycaemia ( $\geq 2$ CBGs $>11 \mathrm{mmol} / \mathrm{L}$ ) should prompt treatment. CBGs $<14 \mathrm{mmol} / \mathrm{L}$ may respond to oral hypoglycaemic agents. Higher levels should be treated with intravenous or subcutaneous insulin, with once daily NPH insulin as a suggested starting regimen.

As immunosuppression doses reduce, hyperglycaemia may improve or resolve. Insulin doses must be reduced accordingly, and the patient must be taught to self-test glucose levels and adjust insulin doses. Input from the diabetes specialist team is important.

In the absence of randomised controlled trials, the management of PTDM should follow that of T2D. There is currently no evidence that tight glycaemic control will improve graft or patient outcomes in PTDM, so glycaemic targets should be individualised according to age, co-morbidity, ability to self-manage and patient preference. ${ }^{28}$ Safe options for oral hypoglycaemics include metformin (if renal function allows), dipeptidylpeptidase-4 inhibitors (of which linagliptin can be used in any level of renal function), glitazones and meglitinides/sulfonylureas (although hypoglycaemic risk and weight gain must be considered). ${ }^{57}$ GLP-1RAs may be useful if weight gain is a concern..$^{58}$ The potential for increased risk of genitourinary infection has led to concern over the use of SGLT-2i in the post-transplant setting, but a small trial of 44 patients with PTDM randomised to empagliflozin or placebo showed a modest glucose benefit, but with significant weight loss, and no increase in risk of infections. ${ }^{59}$

Change in immunosuppression regimen may aid the management of hyperglycaemia. If feasible, consideration may be given for conversion of tacrolimus to ciclosporin or mycophenolate mofetil plus azathioprine in patients with difficult to control hyperglycaemia. ${ }^{60}$

All patients with established PTDM must be put on to a primary care diabetes register and undergo structured diabetes care, including referral to structured diabetes education and regular screening for complications (eyes, feet and kidneys). In addition, they require control of cardiovascular risk factors such as smoking cessation, statin therapy and anti-hypertensive therapy aiming for blood pressure $<130 / 80 \mathrm{mmHg}$.

Patients with PTDM may be most effectively managed in a multidisciplinary setting with diabetes and transplant specialists co-managing the patient.

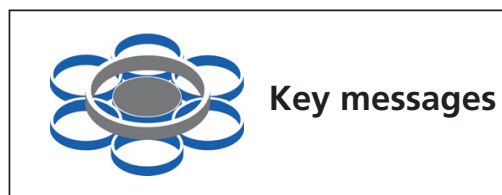

- SGLT-2i agents provide renal and cardiovascular protection in people with Type 2 diabetes and DKD

- PTDM is an important clinical condition and requires active detection and management

- Diabetes management in patient on HD may be challenging, and consideration should be given to the use of diagnostic CGM or Flash GM in such patients

Managing people with diabetes on haemodialysis (HD) Diabetes is common in people on $\mathrm{HD}$, and may occur prior to or during dialysis therapy. Managing glycaemia in people with diabetes on HD is uniquely challenging. Glycaemic variability is exacerbated in people with diabetes on HD, as HD clears glucose and glucoregulatory hormones (insulin and glucagon); dialysisrelated improvement in uraemia, acidosis and hyperphosphataemia can lead to periodic changes in insulin secretion, and symptoms of hypoglycaemia can often be confused with hypotension. ${ }^{61,62}$ Assessment of glycaemia may be difficult due to problems in interpreting $\mathrm{HbA}_{1 \mathrm{c}}$ in renal anaemia. ${ }^{63}$ Therefore, glycaemic management may be reliant on self-monitoring of blood glucose, an additional burden on patients undergoing already burdensome therapy.

Guidance on the management of diabetes in patients on $\mathrm{HD}$ has been published by the Joint British Diabetes Societies in 2016, ${ }^{64}$ and is due to be updated in 2021. There is growing evidence that asymptomatic hypoglycaemia is common in people undergoing $\mathrm{HD}$, and that this may contribute to adverse outcomes. ${ }^{65}$ With a significant improvement in glucose monitoring technology available for managing people with diabetes, it may be appropriate to consider intermittent 'diagnostic' use of flash or continuous glucose monitoring in high-risk patients on HD, especially those on insulin or sulfonylurea. Indeed, NHS guidance on the use of FreeStyle Libre includes people with any form of diabetes on haemodialysis and on insulin treatment. ${ }^{66}$

\section{Conclusions}

A paradigm shift in the management of early DKD using SGLT2i irrespective of glycaemic control is now established and needs to be implemented safely. Most international guidelines now recommend these agents as at least second-line treatment following metformin in people with T2D and, in addition, GLP-RAs are high in the therapeutic pathway. European Society of Cardiology guidelines suggest use of SGLT2i in renal disease even in metformin-naïve patients. ${ }^{67}$

Recent guidance on PTDM suggests that the condition is an important risk marker for early and late graft failure and mortality. Immediate post-transplant hyperglycaemia requires active monitoring and management. Once PTDM is established, treatment targets and pathways should be as for T2D. 
Figure 1. Pathway for diagnosis and management of post-transplant diabetes mellitus

\section{PREOPERATIVE}

- Establish risk factors for diabetes (obesity, family history, previous GDM, high risk ethnic group, glucocorticoid therapy).

Monitor FPG and HbA $1 \mathrm{c}$ ideally 6-monthly (high risk if FPG 6.1-6.9 mmol/L or $\mathrm{HbA}_{1 \mathrm{c}} 42-47 \mathrm{mmol} / \mathrm{mol}(6.1-6.4 \%$ ).

If high risk for diabetes, advise weight loss, increased exercise and improved diet, smoking cessation.

If $\mathrm{HbA} 1 \mathrm{c} \geq 48 \mathrm{mmol} / \mathrm{mol}$ or $F \mathrm{PG} \geq 7.0 \mathrm{mmo} / \mathrm{L}$ on two occasions, diagnose diabetes and put on to standard diabetes pathway.

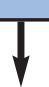

- Monitor afternoon CBG readings.

If CBG persistently $(x 2)>11.0 \mathrm{mmol} / \mathrm{L}$ consider therapy.

If CBG 11-13.9 mmol/L, patient is eating and clinically well, consider oral hypoglycaemic therapy (metformin [if eGFR > $30 \mathrm{~mL} / \mathrm{min}$ ], DPP-4i or sulfonylurea singly or in combination may be used).

- If CBG >14.0 mmol/L on two occasions, commence insulin.

o If clinically unstable and/or not eating, give VRIII with IV $5 \%$ glucose.

o If clinically stable and eating, commence s/c NPH insulin 10 units and rapidly titrate.

o Consider adding metformin if no contraindications.

o CBG target 4-12 mmol/L.

o Refer for dietetic advice to reduce glycaemic excursions.

o Refer for education regarding insulin therapy and CBG monitoring, and undergo regular follow by a health professional with expertise in diabetes management.

o Ensure primary care are aware of diagnosis of post-transplant hyperglycaemia.

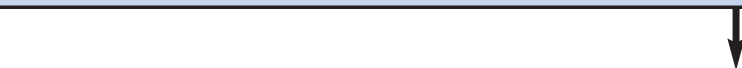

\section{UPTO 6 WEEKS POSTOPERATIVE}

Regular review with aim to reduce glucocorticoid dose, stabilise immunosuppression, consider conversion to less diabetogenic CNI therapy (eg, ciclosporin) if no signs of rejection and stable graft function.

Reduce oral hypoglycaemic therapy or insulin if possible.

Ensure diet and lifestyle changes are optimised.

At 6 weeks, consider OGTT if practical.

During OGT, if FPG $\geq 7.0 \mathrm{mmol} / \mathrm{L}$ or 2 -hour PG $\geq 11.1 \mathrm{mmol} / \mathrm{L}$, diagnose PTDM and treat as below.

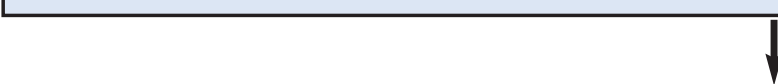

\section{MONTHS POSTOPERATIVE}

If $\mathrm{CBG}$ well controlled and $\mathrm{HbA}_{1 \mathrm{c}}$ at target, consider reduction in anti-hyperglycaemic therapy with careful self-monitoring of $\mathrm{CBG}$.

If hyperglycaemia resolved (CBG $<11 \mathrm{mmo} / \mathrm{L}$ ) off anti-hyperglycaemic therapy, screen for PTDM with OGTT if possible, but if not, request $\mathrm{Hb} \mathrm{A}_{1 \mathrm{c}}$ and FPG.

- If $\mathrm{HbA}_{1 \mathrm{c}} \geq 48 \mathrm{mmol} / \mathrm{mol}$ or FPG $\geq 7.0 \mathrm{mmol} / \mathrm{L}$ on two occasions diagnose PTDM

- Ensure patient and their primary healthcare team are informed of the diagnosis and the diagnosis is coded on the patient's electronic care record.

- Refer patient for structured education and regular screening of eyes, feet, kidneys, blood pressure, weight, smoking status and lipids.

o Manage cardiovascular risk factors.

o Individualise glycaemic target according to patient's preference and co-morbidities.

o Drugs such as metformin (if eGFR $>30 \mathrm{~mL} / \mathrm{min} / 1.73 \mathrm{~m}^{2}$ ), gliptins, GLP-1 analogues, and insulin can all be used safely post transplantation.

- Avoid pioglitazone and saxagliptin in heart failure.

o Seek specialist advice when considering SGLT2 inhibitors.

- If $\mathrm{HbA}_{1 \mathrm{c}}<42 \mathrm{mmol} / \mathrm{mol}(6.0 \%)$ and FPG $<6.0 \mathrm{mmol} / \mathrm{mol}$, PTDM is not diagnosed and hyperglycaemia has resolved.

0 Continue to monitor $\mathrm{HbA}_{1 \mathrm{c}}$ and $\mathrm{FPG}$ at 12 months and then annually.

- If $\mathrm{HbA}_{1 \mathrm{c}} 42-47 \mathrm{mmol} / \mathrm{mol}(6.0-6.4 \%)$ or FPG $6.1-6.9 \mathrm{mmol} / \mathrm{L}$, patient is at risk of developing PTDM

o Continue to monitor $\mathrm{HbA}_{1 \mathrm{c}}$ and $\mathrm{FPG}$ at 6-monthly intervals.

o Offer lifestyle advice to reduce risk of developing PTDM.

FPG, fasting plasma glucose; $\mathrm{HbA}_{1}$, glycated haemoglobin; CBG, capillary blood glucose; DPP-4i, dipeptidylpeptidase-4 inhibitor; VRIII, variable rate intravenous infusion of insulin; NPH, Neutral protamine Hagedorn; CNI, calcineurin inhibitor; 2-hour PG, 2-hour plasma glucose; eGFR, estimated glomerular filtration rate; PTDM, post-transplant diabetes mellitus; SGLT2, sodium glucose transporter-2. 
People with diabetes on HD have a significant risk of adverse effects from anti-hyperglycaemic therapy, and newer technologies may enable their care to be made safer.

The year 2020 will be remembered for its unique healthcare challenges related to the COVID-19 pandemic. In DKD, however, it has been an important year, with a number of seminal publications enabling people living with this condition, and their physicians, to hope for better outcomes in the future.

Author contributorship JT and TAC contributed equally to this article.

\section{Conflict of interest None. Funding None.}

\section{References}

1. Kainz A, Hronsky M, Stel VS, et al. Prediction of prevalence of chronic kidney disease in diabetic patients in countries of the European Union up to 2025. Nephrol Dial Transplant 2015;30(Suppl 4):iv113-8. https://doi.org/ 10.1093/ndt/gfv073

2. Adler Al, Stevens RJ, Manley SE, et al. on behalf of the UKPDS GROUP Development and progression of nephropathy in type 2 diabetes: The United Kingdom Prospective Diabetes Study (UKPDS 64). Kidney Int 2003:63:22532. https://doi.org/10.1046/j.1523-1755.2003.00712.x

3. Koye DN, Shaw JE, Reid CM, et al. Incidence of chronic kidney disease among people with diabetes: a systematic review of observational studies. Diabet Med 2017;34:887-901. https://doi.org/10.1111/dme.13324

4. Fox CS, Matsushita K, Woodward M, et al. Associations of kidney disease measures with mortality and end-stage renal disease in individuals with and without diabetes: a meta-analysis. Lancet 2012;380:1662-73. https://doi.org/10.1016/S0140-6736(12)61350-6

5. Ruggenenti P, Perna A, Gherardi G, et al. Renoprotective properties of ACEinhibition in non-diabetic nephropathies with non-nephrotic proteinuria. Lancet 1999;354:359-64. https://doi.org/10.1016/S0140-6736(98)10363-X

6. Fried L, Emanuele N, Zhang J, et al. Combined angiotensin inhibition for the treatment of diabetic nephropathy. N Engl J Med 2013;369:1892-903. https://doi.org/10.1056/NEJMoa1303154

7. Parving $\mathrm{H}$, Brenner $\mathrm{B}, \mathrm{McM}$ urray J, et al. Cardiorenal end points in a trial of aliskiren for type 2 diabetes. N Engl J Med 2012;367:2204-13. https://doi.org/10.1056/NEJMoa1208799

8. De Zeeuw D, Akizawa T, Audhya P, et al. Bardoxolone methyl in type 2 diabetes and stage 4 chronic kidney disease. N Engl J Med 2013;369: 2492-503. https://doi.org/10.1056/NEJMoa1306033

9. Mann J, Green D, Jamerson K, et al. Avosentan for overt diabetic nephropathy. J Am Soc Nephrol 2010;21(3):527-35. https://doi.org/10.1681/ ASN.2009060593

10. Fioretto P, Zambon A, Rossato M, Busetto L, Vettor R. SGLT2 inhibitors and the diabetic kidney. Diabetes Care 2016;39(Suppl 2):S165-71. https://doi.org/10.2337/dcS15-3006

11. Van Bommel EJM, Muskiet MHA, van Baar MJB, et al. The renal hemodynamic effects of the SGLT2 inhibitor dapagliflozin are caused by postglomerular vasodilatation rather than pre-glomerular vasoconstriction in metformin-treated patients with type 2 diabetes in the randomized, double-blind RED trial. Kidney Int 2020;97:202-12. https://doi.org/10.1016/ j.kint.2019.09.013

12. Wanner C, Inzucchi SE, Lachin JM, et al. Empagliflozin and progression of kidney disease in type 2 diabetes. N Engl J Med 2016;375:323-34. https://doi.org/10.1056/NEJMoa1515920

13. Barnett AH, Mithal A, Manassie J, et al. Efficacy and safety of empagliflozin added to existing antidiabetes treatment in patients with type 2 diabetes and chronic kidney disease: a randomised, double-blind, placebo-controlled trial. Lancet Diabetes Endocrinol 2014;2:369-84. https://doi.org/10.1016/ S2213-8587(13)70208-0

14. Packer M, Anker J, Butler G, et al, for the Emperor-Reduced Trial Investigators. Cardiovascular and renal outcomes with empagliflozin in heart failure. N Engl J Med 2020;383:1413-24. https://doi.org/10.1056/ NEJMoa2022190
15. Neal B, Perkovic V, Mahaffey KW, et al. Canagliflozin and cardiovascular and renal events in type 2 diabetes. N Engl J Med 2017;377:644-57. https://doi.org/10.1056/NEJMoa1611925

16. Perkovic V, Jardine MJ, Neal B, et al. Canagliflozin and renal outcomes in type 2 diabetes and nephropathy. N Engl J Med 2019;380:2295-306. https://doi.org/10.1056/NEJMoa1811744

17. McMurray JJV, Solomon SD, Inzucchi SE, et al. Dapagliflozin in patients with heart failure and reduced ejection fraction. N Engl J Med 2019; 381:1995-2008. https://doi.org/10.1056/NEJMoa1911303

18. Heerspink HJL, Stefánsson BV, Correa-Rotter R, et al. Dapagliflozin in patients with chronic kidney disease. N Engl J Med 2020;383:1436-46. https://doi.org/10.1056/NEJMoa2024816

19. Wiviott SD, Raz I, Bonaca MP, et al. Dapagliflozin and cardiovascular outcomes in type 2 diabetes. N Eng/ J Med 2019;380:347-57. https://doi.org/ 10.1056/NEJMoa1812389

20. Lo KB, Gul F, Ram P, et al. The effects of SGLT2 inhibitors on cardiovascular and renal outcomes in diabetic patients: a systematic review and meta-analysis. Cardiorenal Med 2020;10:1-10. https://doi.org/10.1159/ 000503919

21. Cherney DZ, Zinman B, Inzucchi SE, et al. Effects of empagliflozin on the urinary albumin-to-creatinine ratio in patients with type 2 diabetes and established cardiovascular disease: an exploratory analysis from the EMPAREG OUTCOME randomised, placebo-controlled trial. Lancet Diabetes Endocrinol 2017;5:610-21. https://doi.org/10.1016/S22138587(17)30182-1

22. Neuen BL, Ohkuma T, Neal B, et al. Effect of canagliflozin on renal and cardiovascular outcomes across different levels of albuminuria: data from the CANVAS Program. J Am Soc Nephrol 2019;30:2229-42. https://doi.org/ 10.1681/ASN.2019010064

23. Heerspink HJL, Karasik A, Thuresson M, et al. Kidney outcomes associated with use of SGLT2 inhibitors in real-world clinical practice (CVD-REAL 3): a multinational observational cohort study. Lancet Diabetes Endocrinol 2020;8:27-35. https://doi.org/10.1016/\$2213-8587(19)30384-5

24. Pasternak B, Wintzell $V$, Melbye $M$, et al. Use of sodium-glucose co-transporter 2 inhibitors and risk of serious renal events: Scandinavian cohort study. BMJ 2020;369:m1186. https://doi.org/10.1136/bmj.m1186

25. Empagliflozin SPC. www.medicines.org.uk/emc/product/5441 [Accessed January 2021].

26. Dapagliflozin SPC. www.medicines.org.uk/EMC/medicine/27188 [Accessed January 2021]

27. Canagliflozin SPC. www.medicines.org.uk/emc/medicine/28400 [Accessed January 2021]

28. Buse JB, Wexler DJ, Tsapas A, et al. 2019 update to: Management of Hyperglycemia in Type 2 Diabetes, 2018. A Consensus Report by the American Diabetes Association (ADA) and the European Association for the Study of Diabetes (EASD). Diabetes Care 2020;43:487-93. https://doi.org/ 10.2337/dci19-0066

29. Thong KY, Yadagiri M, Barnes DJ, et al. Clinical risk factors predicting genital fungal infections with sodium-glucose cotransporter 2 inhibitor treatment The ABCD nationwide dapagliflozin audit. Prim Care Diabetes 2018;12:4550. https://doi.org/10.1016/j.pcd.2017.06.004

30. FDA Drug Safety Communication: FDA revises labels of SGLT2 inhibitors for diabetes to include warnings about too much acid in the blood and serious urinary tract infections. US Food and Drug Administration. www.fda.gov/Drugs/DrugSafety/ucm475463.htm

31. Qian BB, Chen Q, Li L, Yan C-F. Association between combined treatment with SGLT2 inhibitors and metformin for type 2 diabetes mellitus on fracture risk: a meta-analysis of randomized controlled trials. Osteoporosis Int 2020;31:2313-20. https://doi.org/10.1007/s00198-020-05590-y

32. Cahn A, Melzer-Cohen C, Pollack R, Chodick G, Shalev V. Acute renal outcomes with sodium-glucose co-transporter-2 inhibitors: real-world data analysis. Diabetes Obes Metab 2019;21:340-8. https://doi.org/10.1111/ dom.13532

33. Pfeffer MA, Claggett B, Diaz R, et al. Lixisenatide in patients with type 2 diabetes and acute coronary syndrome. N Engl J Med 2015; 373:2247-57. https://doi.org/10.1056/NEJMoa1509225

34. Holman RR, Bethel MA, Mentz RJ, et al. Effects of once-weekly exenatide on cardiovascular outcomes in type 2 diabetes. N Engl J Med 2017; 377:1228-39. https://doi.org/10.1056/NEJMoa1612917 
35. Mann JFE, Ørsted DD, Brown-Frandsen K, et al. Liraglutide and renal outcomes in type 2 diabetes. N Eng/ J Med 2017;377:839-48. https://doi.org/ 10.1056/NEJMoa1616011

36. Davies MJ, Bain SC, Atkin SL, et al. Efficacy and safety of liraglutide versus placebo as add-on to glucose-lowering therapy in patients with type 2 diabetes and moderate renal impairment (LIRA-RENAL): a randomized clinical trial. Diabetes Care 2015;39:222-30. https://doi.org/10.2337/ dc14-288

37. Gerstein HC, Colhoun HM, Dagenais GR, et al. Dulaglutide and cardiovascular outcomes in type 2 diabetes (REWIND): a double-blind, randomised placebo-controlled trial. Lancet 2019;394:121-30. https://doi.org/ 10.1016/S0140-6736(19)31149-3

38. Gerstein HC, Colhoun H, Dagenais G, et al. Dulaglutide and renal outcomes in type 2 diabetes: an exploratory analysis of the REWIND randomised, placebo-controlled trial. Lancet 2019;394:131-8. https://doi.org/10.1016/ S0140-6736(19)31150-X

39. Marso SP, Bain SC, Consoli A, et al. Semaglutide and cardiovascular outcomes in patients with type 2 diabetes. N Engl J Med 2016;375:1834-44. https://doi.org/10.1056/NEJMoa1607141

40. Mosenzon O, Blicher TM, Rosenlund S, et al, PIONEER 5 Investigators. Efficacy and safety of oral semaglutide in patients with type 2 diabetes and moderate renal impairment (PIONEER 5): a placebo-controlled, randomised, phase 3a trial. Lancet Diabetes Endocrino/ 2019;7:515-27. https://doi.org/ 10.1016/S2213-8587(19)30192-5

41. Idorn T, Knop FK, Jørgensen MB, et al. Safety and efficacy of liraglutide in patients with type 2 diabetes and end-stage renal disease: an investigatorinitiated, placebo-controlled, double-blind, parallel-group, randomized trial. Diabetes Care 2016;39:206-13. https://doi.org/10.2337/ dc15-1025

42. Tuttle KR, Lakshmanan MC, Rayner B, et al. Dulaglutide versus insulin glargine in patients with type 2 diabetes and moderate-to-severe chronic kidney disease (AWARD-7): a multicentre, open-label, randomised trial. Lancet Diabetes Endocrinol 2018;6(8):605-17.

43. Husain M, Birkenfeld AL, Donsmark M, et al. Oral semaglutide and cardiovascular outcomes in patients with type 2 diabetes. N Engl J Med 2019;381:841-51. https://doi.org/10.1056/NEJMoa1901118

44. Kristensen SL, Rørth R, Jhund PS, et al. Cardiovascular, mortality, and kidney outcomes with GLP-1 receptor agonists in patients with type 2 diabetes: a systematic review and meta-analysis of cardiovascular outcome trials. Lancet Diabetes Endocrinol 2019;7:776-85. https://doi.org/10.1016/ S2213-8587(19)30249-9

45. Nauck MA, Meier JJ, Cavender MA, El Aziz MA, Drucker DJ. Cardiovascular actions and clinical outcomes with glucagon-like peptide-1 receptor agonists and dipeptidyl peptidase-4 inhibitors. Circulation 2017;136:849-70. https://doi.org/10.1161/CIRCULATIONAHA.117.028136

46. Mann JFE, Hansen T, Idorn T, et al. Effects of once-weekly subcutaneous semaglutide on kidney function and safety in patients with type 2 diabetes: a post-hoc analysis of the SUSTAIN 1-7 randomised controlled trials. Lancet Diabetes Endocrinol 2020;8:880-93. https://doi.org/10.1016/ S2213-8587(20)30313-2

47. https://clinicaltrials.gov/ct2/show/NCT03819153 [Accessed January 2021]

48. Bakris GL, Agarwal R, Anker SD, et al; FIDELIO-DKD Investigators. Effect of finerenone on chronic kidney disease outcomes in type 2 diabetes. $N$ Engl J Med 2020;383(23):2219-29. https://doi.org/10.1056/NEJMoa2025845

49. Yates CJ, Fourlanos S, Hejlmesaeth J, Colman PG, Cohney SG. New onset diabetes after kidney transplantation - changes and challenges. Am J Transplant 2012;12:820-8. https://doi.org/10.1111/j.1600-6143.2011.03855.x

50. Kuo HT, Sampaio MS, Vincenti F, Bunnapradist S. Associations of pretransplant diabetes mellitus, new-onset diabetes after transplant, and acute rejection with transplant outcomes: an analysis of the Organ Procurement and Transplant Network/United Network for Organ Sharing (OPTN/UNOS) database. Am J Kidney Dis 2010;56:1127-39. https://doi.org/10.1053/ j.ajkd.2010.06.027

51. Chowdhury TA, Wahba M, Mallik R, et al. Association of British Clinical Diabetologists and Renal Association guidelines on the detection and management of diabetes post solid organ transplantation. Diabet Med 2021; Jan 12:e14523. https://doi.org/10.1111/dme.14523

52. Rodrigo E, Santos L, Piñera C, et al. Prediction at first year of incident new- onset diabetes after kidney transplantation by risk prediction models. Diabetes Care 2012:35:471-3. https://doi.org/10.2337/dc11-2071

53. Øzbay LA, Smidt K, Mortensen DM, et al. Cyclosporin and tacrolimus impair insulin secretion and transcriptional regulation in INS-1E beta-cells. Br J Pharmacol 2011;162(1):136-46. https://doi.org/10.1111/j.14765381.2010.01018.x

54. Webster AC, Woodroffe RC, Tayloer RS, Chapman JR, Craig JC. Tacrolimus versus cyclosporin as primary immunosuppression for kidney transplant recipients: meta-analysis and meta-regression of randomised trial data. BMJ 2005;331:810. https://doi.org/10.1136/bmj.38569.471007.AE

55. Gupta S, Pollack T, Fulkerson C, et al. Hyperglycemia in the posttransplant period: NODAT vs posttransplant diabetes mellitus. J Endocr Soc 2018;2(11):1314-19. https://doi.org/10.1210/js.2018-00227

56. Sharif $A$, Hecking $M$, de Vries APR, et al. Proceedings from an international consensus meeting on posttransplant diabetes mellitus: recommendations and future directions. Am J Transplant 2014;14:1992-2000. https://doi.org/ 10.1111/ajt.12850

57. Kasiske B, Zeier MG, Chapman JR, et al. KDIGO clinical practice guideline for the care of kidney transplant recipients: a summary. Kidney Int 2010;77(4):299-311. https://doi.org/10.1038/ki.2009.377

58. Singh $P$, Pesavento TE, Washburn $K$, Walsh $D$, Meng $S$. Largest single-centre experience of dulaglutide for management of diabetes mellitus in solid organ transplant recipients. Diabetes Obes Metab 2019; 21(4):1061-5. https://doi.org/10.1111/dom.13619

59. Halden TAS, Kvitne KE, Midtvedt $K$, et al. Efficacy and safety of empagliflozin in renal transplant recipients with posttransplant diabetes mellitus. Diabetes Care 2019;42(6):1067-74. https://doi.org/10.2337/ dc19-0093

60. Oberholzer J, Thielke J, Hatipoglu B, Testa G, Sankary HN, Benedetti E. Immediate conversion from tacrolimus to cyclosporine in the treatment of posttransplantation diabetes mellitus. Transplant Proc 2005;37:999-1000. https://doi.org/10.1016/j.transproceed.2004.12.085

61. Jørgensen MB, Idorn T, Knop FK, et al. Clearance of glucoregulatory peptide hormones during haemodialysis and haemodiafiltration in non-diabetic end-stage renal disease patients. Nephrol Dial Transplant 2015;30(3):51320. https://doi.org/10.1093/ndt/gfu327

62. Mak RHK, DeFronzo RA. Glucose and insulin metabolism in uremia. Nephron 1992:61(4):377-82. https://doi.org/10.1159/000186953

63. Kazempour-Ardebili S, Lecamwasam VL, Dassanyake T, et al. Assessing glycemic control in maintenance hemodialysis patients with type 2 diabetes. Diabetes Care 2009;32(7):1137-42. https://doi.org/10.2337/dc081688

64. Frankel A, Kazempour-Ardebili S, Bedi R, Chowdhury TA, et al. Management of adults with diabetes on the haemodialysis unit: summary of new guidance from the Joint British Diabetes Societies and Renal Association. Diabet Med 2018:35:1018-26. https://doi.org/10.1111/ dme.1367

65. Mirani M, Berra C, Finazzi S, et al. Inter-day glycemic variability assessed by continuous glucose monitoring in insulin-treated type 2 diabetes patients on hemodialysis. Diabetes Technol Ther 2010;12(10):749-53. https://doi.org/10.1089/dia.2010.0052

66. NHS England. Flash Glucose Monitoring: National arrangements for funding relevant diabetes patients. https://www.england.nhs.uk/wp-content/uploads/2019/03/National-arrangements-for-funding-of-relevant-diabetes-pat ients-June-2020-Updated-final.pdf [Accessed February 2021]

67. Cosentino F, Grant PJ, Aboyans V, et al. 2019 ESC guidelines on diabetes, pre-diabetes, and cardiovascular diseases developed in collaboration with the EASD. The task force for diabetes, pre-diabetes, and cardiovascular diseases of the European Society of Cardiology (ESC) and the European Association for the Study of Diabetes (EASD). Eur Heart J 2013;34:3035-87. https://doi.org/10.1093/eurheartj/eht108

68. Bhatt DL, Szarek M, Pitt B, et al, for the SCORED Trial Investigators. Sotagliflozin in patients with diabetes and chronic kidney disease. $N$ Engl J Med 2021;384(2):129-39. https://doi.org/10.1056/NEJMoa2030186

69. Cannon CP, Pratley R, Dagogo-Jack S, et al, VERTIS CV Investigators. Cardiovascular outcomes with ertugliflozin in type 2 diabetes. N Engl J Med 2020;383(15):1425-35. https://doi.org/10.1056/NEJMoa2004967 